\title{
Ultrasound Guided Infraclavicular Block for Pain Control After Upper Extremity Surgery
}

Derya Yalçın', Dilek Erdoğan Arı $^{2 *}$, Ceren Köksal ${ }^{2}$, Cansu Akın², Sinan Karaca ${ }^{3}$, Özgür Karakuşs ${ }^{3}$

'Department of Anesthesiology and Reanimation, Ersin Arslan Educational and Research Hospital, Gaziantep, Turkey ${ }^{2}$ Department of Anesthesiology and Reanimation, Fatih Sultan Mehmet Educational and Research Hospital, Istanbul, Turkey

${ }^{3}$ Department of Orthopedics and Traumatology, Fatih Sultan Mehmet Educational and Research Hospital, Istanbul, Turkey

*Corresponding Author: Dilek Erdoğan Arı, M.D., Associate Professor, Department of Anesthesiology and Reanimation, Fatih Sultan Mehmet Educational and Research Hospital, Istanbul, Turkey. Tel: +90-5325429022, Email: dilekerdoganari@gmail.com

Received December 7, 2017; Accepted February 6, 2018; Online Published August 19, 2018

\begin{abstract}
Background: Opioids added to local anesthetics for peripheral nerve blocks may intensify analgesia and prolong analgesic and sensorial block duration. These agents may also cause potentiation and prolongation of motor block.

Objective: This study compared the postoperative effects of $30 \mathrm{~mL}$ of $0.25 \%$ bupivacaine $+50 \mathrm{mcg}$ fentanyl and $30 \mathrm{~mL}$ of $0.25 \%$ bupivacaine +100 mcg fentanyl solutions for the ultrasound-guided infraclavicular block in patients undergoing elbow and forearm surgery.

Methods: In this randomized double-blind study, thirty-six patients with risk of ASA class I-III were randomly allocated into 2 randomized groups. Ultrasound-guided infraclavicular blocks with $30 \mathrm{~mL}$ of $0.25 \%$ bupivacaine $+50 \mathrm{mcg}$ fentanyl for group 1 and $30 \mathrm{~mL}$ of $0.25 \%$ bupivacaine $+100 \mathrm{mcg}$ fentanyl for group 2 were performed before patients emerged from general anesthesia. After surgery, pain levels at rest and during movement were evaluated using the 10-cm visual analog scale (VAS) at recovery room admission, at the 15th and 30th minutes in the recovery room, and at the 2nd, 6th, 12th and 24th hours postoperatively. Both morphine and rescue analgesic requirements were recorded. Sensorial and motor block durations, patient satisfaction, and complications related to the infraclavicular block were recorded.

Results: In both groups, no significant difference in VAS pain scores, total morphine and total rescue analgesic requirements, duration of sensorial and motor block, or patient satisfaction were observed. None of the patients experienced any complications.
\end{abstract}

Conclusion: The mixtures of $0.25 \%$ bupivacaine +50 mcg fentanyl and $0.25 \%$ bupivacaine +100 mcg fentanyl showed similar postoperative effects.

Keywords: Analgesia, Brachial Plexus Block, Bupivacaine, Fentanyl, Ultrasonography

\section{Background}

Today, peripheral nerve blocks are frequently used instead of conventional analgesics for the treatment of postoperative pain. Brachial plexus blocks are frequently used for pain control after upper extremity surgery. The use of ultrasound provides fairly good and reliable imaging in such surgery, because the plexus in this region is anatomically superficial.

Ultrasound-guided peripheral nerve blocks both increase the efficiency of the intervention and reduce the amount of local anesthetic solution used as well the rate of access-related complications. ${ }^{1,2}$ The infraclavicular block is a proven technique for postoperative pain control in patients undergoing forearm surgery, including on the distal humerus. In previous brachial plexus block studies, it was shown that the addition of fentanyl to the local anesthetic agent prolonged the analgesic duration and increased the analgesic efficacy., ${ }^{3,4}$ the other hand, the added fentanyl can potentiate the motor block and extend the block duration. ${ }^{5,6}$

\section{Objective}

To determine the optimal amount of fentanyl added, the postoperative effects of a mixture of $30 \mathrm{~mL} 0.25 \%$ bupivacaine $+50 \mathrm{mcg}$ fentanyl were compared with a mixture of $30 \mathrm{~mL} 0.25 \%$ bupivacaine $+100 \mathrm{mcg}$ fentanyl using the ultrasound-guided infraclavicular block in patients undergoing forearm surgery. 


\section{Methods}

Patients admitted to the Department of Orthopedics and Traumatology of Fatih Sultan Mehmet Education and Research Hospital between July 2015 and July 2016 for elbow or forearm surgery were included in this randomized double-blind study. After receiving patients' informed consent, 36 patients with anesthesia risk of ASA class I-III and aged between 18-70 years were randomly allocated to 2 groups, group 1 and group 2, using the sealed envelope method.

Patients with a history of allergy to the drugs used in the study, obesity $\left(\mathrm{BMI}>35 \mathrm{~kg} / \mathrm{m}^{2}\right)$, patients using continuous narcotic analgesics due to chronic pain, upper extremity neurological dysfunction, infection along the injection site, or coagulopathy were excluded from the study. ${ }^{7}$ Information about the $10-\mathrm{cm}$ VAS (visual analog scale) was given to patients before surgery. No premedication was administered.

In the operation room, all patients were monitored with electrocardiography, noninvasive arterial pressure, pulse oximetry, and Bispectral Index ${ }^{\mathrm{TM}}$ (BIS $\left.{ }^{\mathrm{TM}}\right)$. An infusion of $0.7 \mathrm{~mL} / \mathrm{kg} / \mathrm{h}$ sodium chloride $(0.9 \%)$ was administered. Anesthesia induction was performed with $2-3 \mathrm{mcg} / \mathrm{kg}$ fentanyl, 2-3 $\mathrm{mL} / \mathrm{kg}$ propofol, and $0.6 \mathrm{~mL} / \mathrm{kg}$ rocuronium as BIS $<60 \%$. Maintenance of anesthesia was provided by $1 \%$ $2 \%$ sevoflurane inhalation in a $50 / 50 \%$ mixture of $\mathrm{O}^{2} /$ air and remifentanil infusion $(0.05-0.2 \mathrm{mcg} / \mathrm{kg} / \mathrm{min})$ to keep BIS values between $40 \%-60 \%$. At the end of the operation, $73.8 \mathrm{mg}$ of dexketoprofen, $1 \mathrm{~mL} / \mathrm{kg}^{-1}$ of tramadol, and $8 \mathrm{mg}$ of ondansetron were given intravenously.

At the end of the operation, the infraclavicular block was applied with ultrasound guidance before the patient was awakened. At the 8th, 16th and 24th postoperative hour, $25 \mathrm{mg}$ of dexketoprofen was given orally. The infraclavicular block drug was prepared by an anesthetist who was not involved in the study. The anesthetist who did postoperative follow-ups did not know in which group each patient was involved. Moreover, the patients did not know in which group they were involved. Patients were in the supine position during application of the block with the head facing away from the side to be blocked. A linear ultrasonographic probe (Famio 8, Toshiba Ootawarashi, Japan) was placed in the sagittal plane just medial to the coracoid process and rotated as needed to visualize the axillary artery.

A $100-\mathrm{mm}$ peripheral neurostimulator needle $(0.91 \mathrm{x}$ 100 mm, 20 Gauge Stimuplex D Braun ${ }^{\circledR}$ ) was used during the procedure. Under the guidance of ultrasonography, the needle was advanced toward the 7 oclock position of the artery. After intermittent negative aspiration was performed by an assistant to detect possible vessel puncture, the needle site was confirmed with $2-5 \mathrm{~mL}$ of saline. The infraclavicular block was applied with $30 \mathrm{~mL}$ $0.25 \%$ bupivacaine +50 mcg fentanyl for group 1 patients and $30 \mathrm{~mL} 0.25 \%$ bupivacaine $+100 \mathrm{mcg}$ fentanyl for group 2 patients. Local anesthetic spreading in a U-shape around the axillary artery was shown as an ultrasound
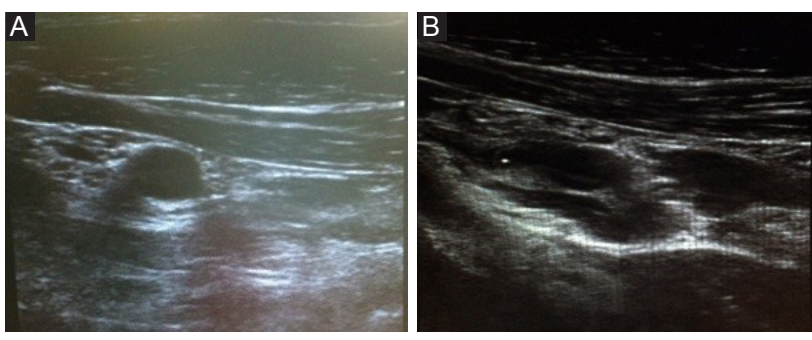

Figure 1. (A) Before and (B) After local anesthetic injection.

image (Figure 1A-B).

Atropine $(0.02 \mathrm{mcg} / \mathrm{kg})$ and neostigmine $(0.05 \mathrm{mcg} /$ $\mathrm{kg}$ ) were administered intravenously for muscle relaxant reversal. Operation and tourniquet times were recorded. Postoperative pain scores at rest and movement at 15th and 30th minutes and 2nd, 6th, 12th, and 24th hours were evaluated with VAS. During postoperative followup, if VAS was higher than $3,0.1 \mathrm{~mL} / \mathrm{kg}$ morphine was administered intramuscularly, and morphine requirement was recorded. If VAS was still higher than 3 one hour after the administration of morphine, $20 \mathrm{mg}$ tenoxicam was administered intravenously as a rescue analgesic. Motor block was assessed by the Modified Bromage Scale $(0=$ no paralysis, $1=$ partial, $2=$ almost complete, $3=$ complete $)$ and sensory block by the pinprick test (scored as $0=$ normal, 1 =impaired, 2 =absent). Nerve block complications, nausea, and vomiting were recorded. Patient satisfaction (a score of $1=$ poor, $4=$ excellent) was evaluated at the 24 th postoperative hour. ${ }^{8}$

The power analysis ( $80 \%$ power and 0.05 type I error) determined that 17 patients were required in each group to detect $2 \mathrm{~cm}$ difference in VAS level with a standard deviation of 2. To account for the possible lack of data collection and exclusion from the study, 18 patients were included in each group.

Data was analyzed using the Statistical Package for Social Sciences 22.0 for IBM (IBM SPSS, Turkey). Convenience of parameters to the normal distribution was assessed using the Shapiro-Wilks test while assessing the study data. Student $t$ test was used to compare quantitative data, for parameters that showed a normal distribution between the two groups, while the Mann-Whitney $U$ test was used to compare data that did not show a normal distribution between the two groups. For within-group comparisons, the paired sample $t$ test was used to compare parameters that showed a normal distribution, and the Wilcoxon signed-rank test was used to compare parameters that did not show a normal distribution. The chi-square and Fisher exact tests were used to compare qualitative parameters. A value of $P \leq 0.05$ was considered statistically significant.

\section{Results}

No significant differences between groups were observed in terms of age, height, weight and BMI, gender distribution, ASA levels, or operation and tourniquet durations $(P>0.05)$ (Table 1).

No difference was observed between groups in terms of 
VAS values at rest $(P>0.05)$.

In both group 1 and group 2; resting VAS values were higher at 24 hours than at other time points $(P<0.01)$ (Table 2).

No difference was observed between groups in terms of VAS values during movement $(P>0.05)$. The VAS values of group 1 and group 2 during movement were higher at the 24th postoperative hour than at other time points $(P<0.01)$ (Table 3$)$.

All of the patients in both groups needed morphine once and tenoxicam once. The time to first analgesic requirement (tenoxicam) was $414.17 \pm 450.14$ minutes in group 1 and $490 \pm 481.43$ minutes in group $2(P>0.05)$; there was no difference between groups.

No difference was observed between groups regarding motor and sensory block offset times $(P>0.05)$ (Table 4$)$.

No difference was observed in postoperative sedation levels between or within the groups $(P>0.05)$ (Table 5).

No difference was observed between groups in terms of patient satisfaction level $(P>0.05)$ (Table 6).

Table 1. Demographic Characteristics and Operation and Tourniquet Duration Compared Between Groups

\begin{tabular}{|c|c|c|c|}
\hline & Group 1 & Group 2 & $\boldsymbol{P}$ \\
\hline Age $(y)$ & $38.44 \pm 1294$ & $39.78 \pm 14.81$ & $0.77^{\mathrm{a}}$ \\
\hline Height (cm) & $172.67 \pm 7.75$ & $169.50 \pm 9.86$ & $0.29^{a}$ \\
\hline Weight (kg) & $76.22 \pm 13.92$ & $77.61 \pm 10.50$ & $0.73^{a}$ \\
\hline BMI $\left(\mathrm{kg} / \mathrm{m}^{2}\right)$ & $25.78 \pm 5.8$ & $27.18 \pm 4.43$ & $0.42^{a}$ \\
\hline \multicolumn{4}{|l|}{ Gender, No. (\%) } \\
\hline Male & $13(72.2)$ & $12(66.7)$ & \multirow{2}{*}{$1.00^{\mathrm{b}}$} \\
\hline Female & $5(27.8)$ & $6(33.3)$ & \\
\hline \multicolumn{4}{|l|}{ ASA, No. (\%) } \\
\hline I & $14(77.8)$ & $9(50)$ & \multirow{3}{*}{$0.24^{b}$} \\
\hline II & $2(11.1)$ & $6(33.3)$ & \\
\hline III & $2(11.1)$ & $3(16.7)$ & \\
\hline Operation duration (min) & $90.56 \pm 36.13$ & $93.06 \pm 35.28$ & $0.83^{a}$ \\
\hline Tourniquet duration (min) & $94.44 \pm 32.89$ & $99.89 \pm 44.84$ & $0.68^{a}$ \\
\hline
\end{tabular}

Values are expressed as mean \pm SD or No. $(\%)$

a Student $t$ test.

${ }^{\mathrm{b}}$ Fisher exact test.

Table 2. Comparison of Resting VAS Values Between Groups

\begin{tabular}{llll}
\hline VAS at Rest & $\begin{array}{l}\text { Group 1 } \\
\text { Mean } \pm \text { SD }\end{array}$ & $\begin{array}{l}\text { Group 2 } \\
\text { Mean } \pm \text { SD }\end{array}$ & $\boldsymbol{P}$ \\
\hline PACU & $0.83 \pm 2.18$ & $0.39 \pm 1.42$ & 0.599 \\
PACU 15th min & $0.83 \pm 1.82$ & $0.39 \pm 1.42$ & 0.367 \\
PACU 30th min & $0.44 \pm 0.86$ & $0.44 \pm 1.25$ & 0.679 \\
Post-op 2nd h & $0.33 \pm 0.77$ & $0.28 \pm 0.96$ & 0.421 \\
Post-op 6th h & $0.28 \pm 0.67$ & $0.72 \pm 1.6$ & 0.551 \\
Post-op 12th h & $1.17 \pm 1.5$ & $0.83 \pm 1.29$ & 0.469 \\
Post-op 24th h & $3.33 \pm 2.09^{\mathrm{a}}$ & $3.06 \pm 2.34^{\mathrm{a}}$ & 0.736 \\
\hline
\end{tabular}

Abbreviation: PACU: post-anesthesia care unit.

Mann Whitney $U$ test.

${ }^{a}$ Wilcoxon sign test; $P<0.01$ when VAS at post-op 24th $\mathrm{h}$ is compared to other time points.

\section{Discussion}

The infraclavicular brachial plexus block provides dense anesthesia for the upper arm, elbow, forearm, and hand. Hadzic et $\mathrm{al}^{9}$ compared general anesthesia and infraclavicular blockage in ambulatory hand surgeries and found that the analgesia score was better with infraclavicular blockade; no additional analgesia was needed, ambulation was earlier, and side effects were fewer.

Successful ultrasound-guided axillary brachial plexus block skills can be learned faster compared to nerve stimulator-guided axillary brachial plexus block. ${ }^{10}$ The ultrasound-guided infraclavicular block is more rapidly performed and provides a higher rate of success when visualization of local anesthetic spread is used as the endpoint for injection rather than neurostimulation. ${ }^{11,12}$ In the current study, failure was not observed due to the advantages of using ultrasound.

Today, many regional anesthetics are combined with general anesthesia. Patients with blocks use less analgesics in the post-anesthesia care unit. They also appear to use less antiemetic drugs. Patients that receive a block

Table 3. Comparison of VAS Values During Movement Between Groups

\begin{tabular}{llll}
\hline VAS at Rest & $\begin{array}{l}\text { Group 1 } \\
\text { Mean } \pm \text { SD }\end{array}$ & $\begin{array}{l}\text { Group 2 } \\
\text { Mean } \pm \text { SD }\end{array}$ & $\boldsymbol{P}$ \\
\hline PACU & $0.83 \pm 2.18$ & $0.39 \pm 1.42$ & 0.599 \\
PACU 15th min & $0.83 \pm 1.82$ & $0.39 \pm 1.42$ & 0.367 \\
PACU 30th min & $0.44 \pm 0.86$ & $0.44 \pm 1.25$ & 0.679 \\
Post-op 2nd h & $0.33 \pm 0.77$ & $0.28 \pm 0.96$ & 0.421 \\
Post-op 6th h & $0.28 \pm 0.67$ & $0.72 \pm 1.6$ & 0.551 \\
Post-op 12th h & $1.22 \pm 1.59$ & $0.83 \pm 1.29$ & 0.447 \\
Post-op 24th h & $3.39 \pm 2.09$ a & $3.06 \pm 2.34^{\mathrm{a}}$ & 0.688 \\
\hline
\end{tabular}

Abbreviation: PACU: post-anesthesia care unit.

Mann Whitney $U$ test .

${ }^{a}$ Wilcoxon sign test; $P<0.01$ when VAS at post-op 24th $\mathrm{h}$ is compared to other time points.

Table 4. Comparison of Motor and Sensory Block Offset Times Between Groups

\begin{tabular}{lccc}
\hline & $\begin{array}{c}\text { Group 1 } \\
\text { Mean } \pm \text { SD }\end{array}$ & $\begin{array}{c}\text { Group 2 } \\
\text { Mean } \pm \text { SD }\end{array}$ & $\boldsymbol{P}$ \\
\hline Motor block offset times $(\mathrm{h})$ & $1.89 \pm 4.47$ & $1.08 \pm 3.34$ & 0.599 \\
Sensory block offset times $(\mathrm{h})$ & $16.58 \pm 4.4$ & $17.67 \pm 4.7$ & 0.224 \\
\hline
\end{tabular}

Mann Whitney $U$ test.

Table 5. Evaluation of Groups According to Postoperative Sedation Score

\begin{tabular}{lccc}
\hline $\begin{array}{l}\text { Postoperative } \\
\text { Sedation Score }\end{array}$ & $\begin{array}{c}\text { Group 1 } \\
\text { Mean } \pm \text { SD }\end{array}$ & $\begin{array}{c}\text { Group 2 } \\
\text { Mean } \pm \text { SD }\end{array}$ & $P$ \\
\hline PACU & $2.28 \pm 0.67(2)$ & $2.44 \pm 0.62(2.5)$ & 0.449 \\
PACU 15th min & $2.28 \pm 0.67(2)$ & $2.39 \pm 0.61(2)$ & 0.634 \\
PACU 30th min & $2.11 \pm 0.32(2)$ & $2.22 \pm 0.55(2)$ & 0.406 \\
Post-op 2nd h & $1.94 \pm 0.54(2)$ & $2.11 \pm 0.32(2)$ & 0.324 \\
Post-op 6th h & $2 \pm 0(2)$ & $2 \pm 0(2)$ & 1.000 \\
Post-op 12th h & $1.94 \pm 0.24(2)$ & $1.94 \pm 0.24(2)$ & 1.000 \\
Post-op 24th h & $1.83 \pm 0.38(2)$ & $1.94 \pm 0.24(2)$ & 0.296 \\
\hline
\end{tabular}

Abbreviation: PACU: post-anesthesia care unit. Mann Whitney $U$ test. 
Table 6. Patient Satisfaction Assessment

\begin{tabular}{llllll}
\hline & Poor (1) & Moderate (2) & Good (3) & Excellent (4) & $\boldsymbol{P}$ Value \\
\hline Group 1 & 0 & 0 & 3 & 15 & 0.549 \\
Group 2 & 0 & 1 & 2 & 15 & 0.549 \\
\hline
\end{tabular}

Fisher exact test.

have statistically shorter post-anesthesia care unit stays. Moreover, the use of peripheral nerve blocks reduces the use of post-op narcotics, which may be related to the lower use of postoperative antiemetic drugs observed. ${ }^{13}$

Opioids are the most frequently used local anesthetic adjuvants. The use of these drugs in neuraxial blocks has evolved over the last 50 years. The opioids potentiate antinociception of local anesthetics by G-protein coupled receptor mechanisms by causing hyperpolarization of the afferent sensory neurons. The extent of efficacy of the block is determined by the dose, site of injection, lipophilicity, and the acid-base milieu of the site of drug deposition. ${ }^{14}$

The current study compared the effects of adding fentanyl to local anesthetics in the infraclavicular brachial plexus block. It was observed that changes in the fentanyl dose added to bupivacaine at the infraclavicular block did not alter postoperative pain level, duration of analgesic effect, additional analgesic requirement, or sensory and motor block offset times.

In their review (including 22 studies and 1732 participants), Chin et $\mathrm{al}^{15}$ suggested the infraclavicular block as an excellent choice for surgical anesthesia of the lower arm. It is as safe and effective as any other technique of brachial plexus block, regardless of whether ultrasound or neurostimulation guidance is used. The infraclavicular block is an effective technique for providing surgical anesthesia of the lower arm, with an average success rate of $88 \%$ in the studies included in this review. One advantage of this block over other brachial plexus blocks is the decreased incidence of tourniquet pain, which may reduce the need for additional intraoperative sedoanalgesia.

Kilka et $\mathrm{al}^{16}$ reported that they performed the successful injection of $400 \mathrm{mg}$ of $1 \%$ prilocaine $+50 \mathrm{mg}$ of $0.5 \%$ bupivacaine on the infraclavicular block technique in 175 patients. They achieved a successful block in $94.8 \%$, and postoperative analgesia lasted approximately 8 hours. In the current study, the time to first postoperative analgesic requirement was $414.17 \pm 450.14$ minutes in group 1 and $490 \pm 481.43$ minutes in group 2 due to the infraclavicular block applied at the end of surgery. No differences were seen between the groups. The highest use of morphine was seen at the first 30 minutes postoperatively. This was because the infraclavicular block activity did not fully start in the early postoperative period and that full effect was obtained after 30 minutes postoperatively. The delayed analgesic effect is thought to be related to the late onset of the infraclavicular block. Neither nausea and vomiting nor systemic toxicity were observed in any of the patients. Moreover, none of the patients had any complication that could be related to the infraclavicular block.
The difference between the local anesthetic dose and volume used in the brachial plexus block and the contents of the solution (such as sodium bicarbonate, adrenaline) may provide different results regarding sensory block development. ${ }^{17}$ Epinephrine is used to prolong the duration of analgesia, and bicarbonate is used to hasten onset. ${ }^{18}$ Vester-Andersen et $\mathrm{al}^{19,20}$ observed that with axillary block with $1 \%$ mepivacaine in 3 different volumes, the sensory block was better with high-volume drugs. Similarly, in another study in which axillary block was applied using the same amount and different volumes of the local anesthetic agent, the quality of the sensory block was better in the high-volume group than in the low-volume group. ${ }^{21}$

In the brachial plexus block, adjuvant drugs are added to both increase the quality of anesthesia and analgesia and prolong the duration of the effects of anesthetics. These drugs can be listed as opioids, clonidine, tramadol, neostigmine, ketamine, adenosine, dexmedetomidine, and somatostatin. ${ }^{18}$ Murphy et $\mathrm{al}^{18}$ scanned retrospectively 24 studies with a total of 796 patients who underwent brachial plexus blocks. The effects of drugs added to the blocks, such as opioids, tramadol, clonidine, and neostigmine, were investigated, and significant analgesic activity of clonidine was shown. For the other drugs, however, they emphasized that additional studies were needed.

Nishikawa et $\mathrm{al}^{5}$ found that the addition of $100 \mathrm{mcg}$ of fentanyl to axillary nerve blocks with lidocaine-epinephrine solution increased block duration by approximately 1 hour. Additionally, Karakaya et $\mathrm{al}^{3}$ showed that the addition of 100 mcg fentanyl to $40 \mathrm{~mL} 0.25 \%$ bupivacaine approximately doubled the analgesic duration in approximately $60 \%$ of patients with axillary brachial plexus block. Sert et al ${ }^{22}$ also demonstrated prolongation of the motor and sensory block as well as the time of first analgesic requirement when fentanyl was added to articaine in axillary blocks. In a study conducted by Zainab et $\mathrm{al}^{23}$ in which $100 \mathrm{mcg}$ fentanyl was added to lignocaine-bupivacaine mixtures in supraclavicular brachial plexus block, the mean onset of sensory and motor block was significantly early and the duration of analgesia was significantly longer. The patients with added fentanyl had no pain up to 4 hours; first pain (VAS $>4$ ) reporting was around 5 hours, and the worst pain was experienced after 8 hours. This study revealed that the addition of fentanyl causes significantly early onset of anesthesia and longer duration of analgesia without any side effects. ${ }^{23}$

\section{Conclusion}

In patients undergoing elbow or forearm surgery, similar results were seen in applying ultrasound-guided infraclavicular blocks with doses of $50 \mathrm{mcg}$ and $100 \mathrm{mcg}$ of fentanyl added to $30 \mathrm{~mL}$ of $0.25 \%$ bupivacaine regarding analgesic efficacy and duration, sensory and motor block intensity and duration, sedation level, and patient satisfaction. Further studies are needed to determine the ideal dose of fentanyl to be added to bupivacaine in infraclavicular block administration. 


\section{Authors' Contributions}

All authors contributed equally to this research.

\section{Conflict of Interest Disclosures}

The authors declare that they have no conflicts of interest.

\section{Ethical Approval}

This study was approved by the local Institutional Review Board (No:2015/13). This randomized clinical trial was registered at the Thai Clinical Trials Registry (TCTR) (identifier: TCTR20180814001; http://www.clinicaltrials. in.th/)

\section{References}

1. Nadeau MJ, Levesque S, Dion N. Ultrasound-guided regional anesthesia for upper limb surgery. Can J Anaesth. 2013;60(3):304320. doi:10.1007/s12630-012-9874-6.

2. Senapathi TGA, Widnyana IMG, Aribawa I, et al. Ultrasoundguided bilateral superficial cervical plexus block is more effective than landmark technique for reducing pain from thyroidectomy. J Pain Res. 2017;10:1619-1622. doi:10.2147/jpr.s138222.

3. Karakaya D, Buyukgoz F, Baris S, Guldogus F, Tur A. Addition of fentanyl to bupivacaine prolongs anesthesia and analgesia in axillary brachial plexus block. Reg Anesth Pain Med. 2001;26(5):434-438. doi:10.1053/rapm.2001.24675.

4. Farooq N, Singh RB, Sarkar A, Rasheed MA, Choubey S. To Evaluate the Efficacy of Fentanyl and Dexmedetomidine as Adjuvant to Ropivacaine in Brachial Plexus Block: A Doubleblind, Prospective, Randomized Study. Anesth Essays Res. 2017;11(3):730-739. doi:10.4103/aer.AER_30_17.

5. Nishikawa K, Kanaya N, Nakayama M, Igarashi M, Tsunoda K, Namiki A. Fentanyl improves analgesia but prolongs the onset of axillary brachial plexus block by peripheral mechanism. Anesth Analg. 2000;91(2):384-387. doi:10.1213/00000539200008000-00028.

6. Paluvadi VR, Manne VS. Effect of Addition of Fentanyl to Xylocaine Hydrochloride in Brachial Plexus Block by Supraclavicular Approach. Anesth Essays Res. 2017;11(1):121124. doi:10.4103/0259-1162.186609.

7. Vazin $M$, Jensen $K$, Kristensen DL, et al. Low-Volume Brachial Plexus Block Providing Surgical Anesthesia for Distal Arm Surgery Comparing Supraclavicular, Infraclavicular, and Axillary Approach: A Randomized Observer Blind Trial. Biomed Res Int. 2016;2016:7094121. doi:10.1155/2016/7094121.

8. Bhardwaj S, Devgan S, Sood D, Katyal S. Comparison of Local Wound Infiltration with Ropivacaine Alone or Ropivacaine Plus Dexmedetomidine for Postoperative Pain Relief after Lower Segment Cesarean Section. Anesth Essays Res. 2017;11(4):940945. doi:10.4103/aer.AER_14_17.

9. Hadzic A, Arliss J, Kerimoglu B, et al. A comparison of infraclavicular nerve block versus general anesthesia for hand and wrist day-case surgeries. Anesthesiology. 2004;101(1):127132. doi:10.1097/00000542-200407000-00020.

10. Luyet C, Schupfer G, Wipfli M, Greif R, Luginbuhl M, Eichenberger U. Different Learning Curves for Axillary Brachial Plexus Block: Ultrasound Guidance versus Nerve Stimulation. Anesthesiol Res Pract. 2010;2010:309462. doi:10.1155/2010/309462.

11. Dingemans E, Williams SR, Arcand G, et al. Neurostimulation in ultrasound-guided infraclavicular block: a prospective randomized trial. Anesth Analg. 2007;104(5):1275-1280, tables of contents. doi:10.1213/01.ane.0000226101.63736.20.

12. Brull R, Lupu M, Perlas A, Chan VW, McCartney CJ. Compared with dual nerve stimulation, ultrasound guidance shortens the time for infraclavicular block performance. Can J Anaesth.

\section{Research Highlights}

\section{What Is Already Known?}

In previous brachial plexus block studies, it has been shown $t$ hat the addition of fentanyl to the local anesthetic agent prolongs the analgesic duration and increases the analgesic efficacy.

\section{What This Study Adds?}

The optimum fentanyl dose is not clear. In this study, it was found that doses of $50 \mathrm{mcg}$ and $100 \mathrm{mcg}$ of fentanyl have similar effects regarding analgesic efficacy and duration, sensory and motor block intensity and duration, sedation level, and patient satisfaction.

2009;56(11):812-818. doi:10.1007/s12630-009-9170-2.

13. Feierman DE, Klinkowitz E, Keilin C, et al. Chart Review of PACU Outcomes for Patients Who Had Ambulatory Shoulder Surgery with Peripheral Nerve Block (PNB) and General Anesthesia Compared to General Anesthesia (GA). Open J Anesthesiol. 2015;5(7):173-176. doi:10.4236/ojanes.2015.57031.

14. Swain A, Nag DS, Sahu S, Samaddar DP. Adjuvants to loca anesthetics: Current understanding and future trends. World J Clin Cases. 2017;5(8):307-323. doi:10.12998/wjcc.v5.i8.307.

15. Chin KJ, Alakkad H, Adhikary SD, Singh M. Infraclavicular brachial plexus block for regional anaesthesia of the lower arm. Cochrane Database Syst Rev. 2013(8):Cd005487. doi:10.1002/14651858.CD005487.pub3.

16. Kilka HG, Geiger $\mathrm{P}$, Mehrkens HH. [Infraclavicular vertica brachial plexus blockade. A new method for anesthesia of the upper extremity. An anatomical and clinical study]. Anaesthesist. 1995;44(5):339-344. doi:10.1007/s001010050162.

17. Lanz E, Theiss D, Jankovic D. The extent of blockade following various techniques of brachial plexus block. Anesth Analg. 1983;62(1):55-58. doi:10.1213/00000539-198301000-00009.

18. Murphy DB, McCartney CJ, Chan VW. Novel analgesic adjuncts for brachial plexus block: a systematic review. Anesth Analg. 2000;90(5):1122-1128. doi:10.1097/00000539-20000500000023

19. Vester-Andersen T, Husum B, Lindeburg T, Borrits L, Gothgen I. Perivascular axillary block IV: blockade following 40, 50 or 60 $\mathrm{ml}$ of mepivacaine $1 \%$ with adrenaline. Acta Anaesthesiol Scand. 1984;28(1):99-105. doi:10.1111/j.1399-6576.1984.tb02020.x.

20. Vester-Andersen T, Christiansen C, Sorensen M, KaalundJorgensen HO, Saugbjerg P, Schultz-Moller K. Perivascular axillary block II: influence of injected volume of local anaesthetic on neural blockade. Acta Anaesthesiol Scand. 1983;27(2):95-98. doi:10.1111/j.1399-6576.1983.tb01913.x.

21. Martin R, Dumais R, Cinq-Mars S, Tetrault JP. [Axillary plexus block by simultaneous blockade of several nerves. I. Influence of the volume of the anesthetic solution]. Ann Fr Anesth Reanim. 1993;12(3):229-232. doi:10.1016/S0750-7658(05)80645-8.

22. Sert H, Muslu B, Usta B, Colak N, Irem Demircioglu R, Gozdemir M. A comparison of articaine and fentanyl-supplemented articaine for hemodialysis fistula creation under ultrasoundguided axillary block. Ren Fail. 2011;33(3):280-284. doi:10.310 9/0886022x.2011.560502.

23. Zainab F, Faruq MO, Talukder $M$, Yeasmeen S, Alam AS, Haque AF. Anaesthetic and analgesic efects of adding fentanyl to bupivacaine-lignocaine mixtures in supraclavicular brachial plexus block a comparative study with or without fentanyl. Bangladesh Med J. 2015;44(1):26-31. doi:10.3329/ bmj.v44i1.26348. 